\title{
LiDAR derived high resolution topography: the next challenge for the analysis of terraces stability and vineyard soil erosion
}

\author{
Federico Preti, ${ }^{1}$ Paolo Tarolli, ${ }^{2}$ Andrea Dani, ${ }^{1}$ Simone Calligaro, ${ }^{2}$ Massimo Prosdocimi ${ }^{2}$ \\ 'Dipartimento di GESAAF, Sezione di Ingegneria Agraria, Forestale e dei Biosistemi Agrari, \\ Università di Firenze, Firenze, Italy; ${ }^{2}$ Department of Land, Environment, Agriculture and Forestry \\ University of Padova, Agripolis, Legnaro (PD), Italy
}

\begin{abstract}
The soil erosion in the vineyards is a critical issue that could affect their productivity, but also, when the cultivation is organized in terraces, increase the risk due to derived slope failure processes. If terraces are not correctly designed or maintained, a progressively increasing of gully erosion affects the structure of the walls. The results of this process is the increasing of connectivity and runoff. In order to overcome such issues it is really important to recognize in detail all the surface drainage paths, thus providing a basis upon which develop a suitable drainage system or provide structural measures for the soil erosion risk mitigation. In the last few years, the airborne LiDAR technology led to a dramatic increase in terrain information. Airborne LiDAR and Terrestrial Laser Scanner derived high-resolution Digital Terrain Models (DTMs) have opened avenues for hydrologic and geomorphologic studies (Tarolli et al., 2009). In general, all the main surface process signatures are correctly recognized using a DTM with cell sizes of $1 \mathrm{~m}$. However sub-meter grid sizes may be more suitable in those situations where the analysis of micro topography related to micro changes is critical for slope failures risk assessment or for the design of detailed drainage flow paths. The Terrestrial Laser Scanner (TLS) has been proven to be an useful tool for such detailed field survey. In this work, we test the effectiveness of high resolution topography derived by airborne LiDAR and TLS for the recognition of
\end{abstract}

Correspondence: Paolo Tarolli, Department of Land, Environment, Agriculture and Forestry, University of Padova, Agripolis, viale dell'Università 16, 35020, Legnaro (PD), Italy.

E-mail: tarolli.paolo@gmail.com

Key words: Soil erosion, terraced slopes, vineyard, LiDAR, TLS, DTM.

Acknowledgements: the Riegl LMS-620 data were elaborated by the Interdepartmental Research Center for Cartography, Photogrammetry, Remote Sensing and GIS at the University of Padova (CIRGE0). Airborne LiDAR data were provided by the Ministry for Environment, Land and Sea (Ministero dell'Ambiente e della Tutela del Territorio e del Mare, MATTM), within the framework of the 'Extraordinary Plan of Environmental Remote Sensing' (Piano Straordinario di Telerilevamento Ambientale, PST-A).

(C) Copyright P. Tarolli et al., 2013

Licensee PAGEPress, Italy

Journal of Agricultural Engineering 2013; XLIV(s2):e16

doi:10.4081/jae.2013.s2.e16

This article is distributed under the terms of the Creative Commons Attribution Noncommercial License (by-nc 3.0) which permits any noncommercial use, distribution, and reproduction in any medium, provided the original author(s) and source are credited. areas subject to soil erosion risk in a typical terraced vineyard landscape of "Chianti Classico" (Tuscany, Italy). The algorithm proposed by Tarolli et al. (2013), for the automatic recognition of anthropic feature induced flow direction changes, has been tested. The results underline the effectiveness of LiDAR and TLS data in the analysis of soil erosion signatures in vineyards, and indicate the high resolution topography as a useful tool to improve the land use management of such areas. The stability conditions have been analyzed under the influence of the measured geometry alterations of the wall structure.

\section{Introduction}

Extended terraced slopes are a distinctive characteristic of landscapes all over the Italian peninsula. The terraces, in fact, allow the farming of many precious products, such as wine, also on very steep slopes. In this terraced landscape, the human interference on the natural morphology is evident, but terraces represent also a typical case of the ancient blending of anthropic communities and lands. Terraced vineyards, as much as olivegrove, are probably the most typical landscape in Tuscany, and the Chianti wine is one of the most prestigious wine produced in Tuscany, exported and appreciated all over the word. Neverthless, these terraced rural areas have gone through a series of social and economical changes that caused, since the Sixties, a gradual abandonement of the traditional agricultural practices and of the maintenance of the rural landscape. A serious consequence following the lack of maintenance of terraced slopes is the increasing erosion due to the loss of efficiency of drainage systems (Crosta et al., 2003). Uncontrolled erosion in agricultural lands causes not negligible soil and nutrient losses (Poesen and Hooke, 1997; Douglas et al., 1998; Corell et al., 1999; Steegen et al., 2001; Verstraeten and Poesen, 2002; $\mathrm{Ng}$ Kee et al., 2002; Ramos and Martìnez-Casanovas, 2004) and the long-term productivity loss of degraded soil and plot level (Roose, 1996; Woodward, 1999), with a severe economic impact on farms (MartìnezCasanovas et al., 2005). The consequences of a strong soil erosion in terraced areas are serious, with possible negative effects over people's safety. In terraced slopes, in fact, concentrated flow incises rills and gullies that can damage retaining walls (Figure 1) and trigger small slides and slumps (Crosta et al., 2003).

Due to the flow concentration during high-intensity or moderateintensity but prolonged rainstorms, or after snow melting, small slides can evolve in shallow landslides (Moser and Hohensinn, 1983; Crosta, 1998; Crosta e Frattini, 2002) such as soil slips and debris flow that can travel distances up to several hundred meters (Crosta et al., 2003).

According to Crosta et al. (2003), terraces produce great changes in slopes hydrologic setting enhancing flow concentration and infiltration at specific sites. This explains the important role of morphologyderived hydrologic factors as triggering process of landslides. It is also clear the importance of having effective instruments to assess in a 
detailed way the morphology, to recognize those areas subject to potential erosion and slides. In the last year, many works have demonstrated the effectiveness of high resolution topography derived by Laser Scanner (LiDAR) to generate accurate Digital Terrain Models (DTM) to be considered in many different areas of research. Nowadays, common meter resolution DTMs are useful to recognize all the main surface processes signatures (Tarolli and Dalla Fontana, 2009; Passalacqua et al. 2010; Sofia et al. 2011; Tarolli et al 2012; Sofia et al. 2013a,b). In some specific situation, however, where the surveyed processes are related to micro morphologies, as in the case of terraced vineyard, a sub-meter DTM might be more suitable (Tarolli et al., 2012; Lin et al., 2013). Centimetric resolution DTMs are derivable from spatial data acquired through Terrestrial Laser Scanner (TLS), a LiDAR instrument that has been proven to be a useful tool for such detailed field survey at a hillslope scale. In this context, the aim of this paper is to present the TLS survey and the consecutive spatial data processing of a terraced vineyard subject to soil erosion risk in the typical landscape of "Chianti Classico" wine at Lamole (Tuscany, Italy). High-resolution results are compared with traditional resolution digital topography derived by airborne LiDAR.

\section{Materials and methods}

\section{TLS survey and derived DTMs}

The TLS survey was performed in March 2013. A "time-of-fly" Terrestrial Laser Scanner System Riegl® LMS-Z620 was used. This laser scanner operates in the wavelength of the near infrared and provides a maximum measurement range of $2 \mathrm{~km}$, with an accuracy of 10 $\mathrm{mm}$ and a speed of acquisition up to $11000 \mathrm{pts} / \mathrm{s}$. For each measured point, the system records the range, horizontal and vertical alignment angles, and the backscattered signal amplitude. The laser scanner was integrated with a Nikon ${ }^{\circledR}$ D90 digital camera (12.9 Mpixel of resolution) equipped with a $20 \mathrm{~mm}$ lens, that provided an RGB value to the acquired point cloud (Figure 2).

The TLS survey at Lamole was carried out from six scan positions, in order to capture precisely the complex morphology of the terraced slopes: one position was used for a panoramic high resolution scan of the main terraced slope, and five were considered to model, with a very high resolution, the recently restored wall, displaying signs of failures (see Figure 8 Chapt 3, and Figure 2). From the "panoramic" scan position 5,352,080 elevation points were collected with a resolution of $0.1 \mathrm{~m}$ at $200 \mathrm{~m}$ from the scanner. From the other scan positions $1,452,944$ points were measured on the retaining wall and on its close proximity with a resolution of $0.02 \mathrm{~m}$ at $10 \mathrm{~m}$ from the scanner; other $1,737,818$ points with a resolution of $0.05 \mathrm{~m}$ at $20 \mathrm{~m}$ from the scanner plus $2,254,414$ points with various resolutions were acquired on the surrounding area (Figure 3).In order to georeference the survey in a global coordinate system, a GNSS network was set up. A couple of Topcon HiPer Pro ${ }^{\circledR}$ dual-frequency and dual-constellation receivers were employed. These differential GPS+GLONASS receivers guarantee a horizontal precision of $3 \mathrm{~mm}+0.5 \mathrm{ppm}$ (per baseline length) and a vertical precision of $5 \mathrm{~mm}+0.5 \mathrm{ppm}$ (per baseline length) if used in static or rapid static mode.

The raw spatial data (X, Y, Z measurements) acquired were processed in two steps: first to georeferece them and filter all nonground points, and then to create the DTMs.

The whole processing procedures have been carried out using the Riegl proprietary software RiscanPro®. In particular, with RiscanPro a semi-automatic iterative surface based approach is available to detect non-ground points within a defined range from the real ground surface.

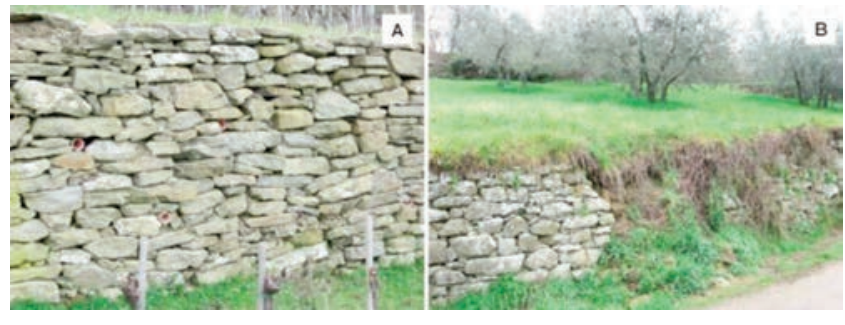

Figure 1. Terraced walls with an implemented drainage system (A), and effects of a failed maintenance $(B)$.

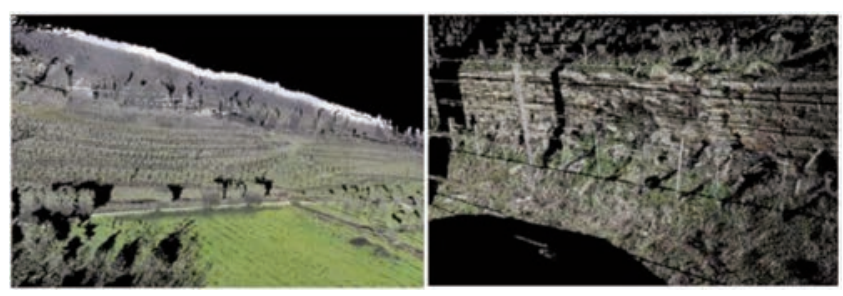

Figure 2. Point cloud derived with TLS with RGB color overlapped to each point.

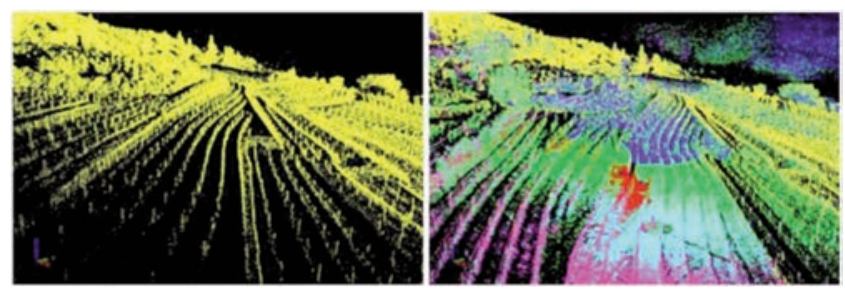

Figure 3. Example of point cloud taken from a single position (left), and overlapping of multiple scans (right).

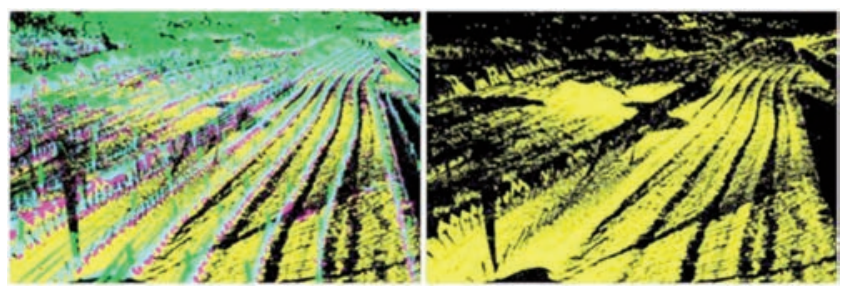

Figure 4. Detail of point cloud of Lamole study area in false colors: yellow points are the groundpoints; fuchsia points are points included from the ground and $50 \mathrm{~cm}$ height from the ground; blue points are points with a distance from the ground range from $50 \mathrm{~cm}$ to $1 \mathrm{~m}$; green points are points above $1 \mathrm{~m}$ from the ground.
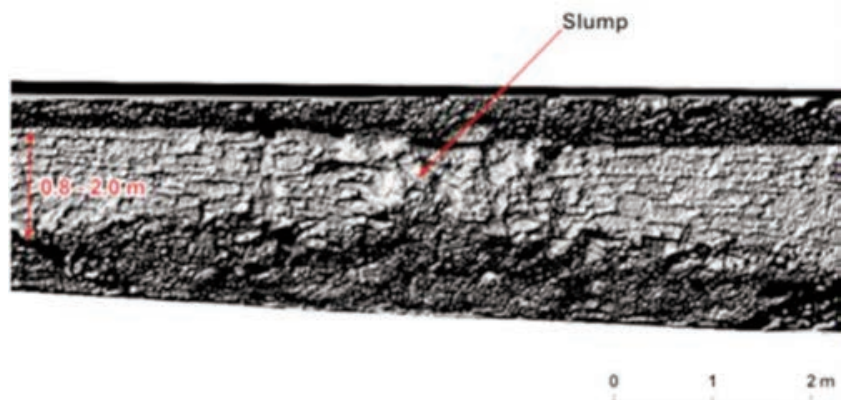

Figure 5. Surveyed retaining wall model hillshade at $0.01 \mathrm{~m}$ resolution. 
Thanks to the algorithm, more and more fitting meshes are created applying a $2.5 \mathrm{D}$ raster filter - this filter generates a $2.5 \mathrm{D}$ raster point cloud of source data; in which that each raster cell will be represented by a single point. The points that lie over a threshold defined from the generated mash are eliminated. In the Lamole case, the minimum distance considered from the ground surface was been $0.2 \mathrm{~m}$. After this iterative process some corrections were necessary, because of the particular morphology, characterized regular big steps rich in vegetation, not easy to model by 2.5D filter. Figure 4 shows an example of the raw point data (A) and the ground point data (B) derived after the filtering procedure. Spatial coordinates of the remaining ground points were exported and elevation values were interpolated by the natural neighbors method (Sibson, 1981) to generate 0.2 and $0.5 \mathrm{~m}$ resolution DTMs of the terraced slope. The ground points density is really irregular on the study area, but at the center of the surveyed terraced slope average ground points density is more than $1000 \mathrm{pts} / \mathrm{m}^{2}$. The absolute vertical accuracy, evaluated by a ground differential DGPS, was estimated to be less than $0.1 \mathrm{~m}$.

\section{Wall modeling}

A centimetric survey of a $120 \mathrm{~m}$ long stretch of wall was carried out from four different scans positions. After a hand-made filtering of vegetation, the topographic information was exported flipping the order of $\mathrm{x}, \mathrm{y}, \mathrm{z}$ values: the coordinates of each point were exported as $-\mathrm{y} ; \mathrm{z} ; \mathrm{x}$. Therefore, a front viewed 3D digital model of the retaining wall was generated interpolating $\mathrm{x}$ value by the natural neighbors method (Sibson, 1981). In the created wall model, with a resolution of $0.01 \mathrm{~m}$, every single stone that compose the wall can be individuate (Figure 5). This level of precision allows to simulate the behavior of the wall in response to back load with a high detail and without many artifacts and much approximations.

\section{Topographic analyses}

To quantify the effect of retaining walls on contributing area distributions (and therefore, on flow paths) within catchments, we applied the Relative Path Impact Index (RPII) index proposed by Tarolli et al. (2013) to quantify the forest road effects on slope stability. This morphometric index is calculated as follows:

$$
\mathrm{RPII}=\ln \left(-\frac{A_{s m}-A_{r}}{A_{s m}}\right)
$$

where $A_{r}$ is the contributing area (computed according to the D-Inf method proposed by Tarboton 1997) evaluated in the presence of any roads or paths on hillslopes, while $A_{s m}$ is the contributing area without morphological alterations on hillslopes.

The negative sign and the logarithmic function is applied to emphasize and map only those areas where an increasing of drainage area is observed due to human induced alteration. The higher the RPII index, the stronger the alteration.

To simulate the absence of anthropogenic features (roads, paths, walls), a smoothed DTM is considered, based on an approximation of the original surface solved within a local moving window. To produce this smoothed surface, we decided to use the bivariate quadratic function introduced by Evans (1979), expressed as:

$$
\boldsymbol{Z}=a x^{2}+b y^{2}+c x y+d x+e y+f
$$

where $\mathrm{x}, \mathrm{y}$, and $\mathrm{Z}$ are local coordinates, and $a$ to $f$ are quadratic coefficients. This function was found to perform well in the presence of elevation errors (Albani et al. 2004; Florinsky 1998), and it has been successfully applied also in several other analysis on Earth surface morphology and feature extraction (Pirotti and Tarolli, 2010; Sofia et al., 2011; Tarolli et al., 2012, Sofia et al. 2013a,b).

\section{Study area}

The study area is in the "Chianti Classico" wine area, in the center of Tuscany, and it is located in the small village of Lamole (Figure 6) within the municipality of Greve in Chianti (province of Florence).

The study area is a typical hilly environment, along a slope facing North-North West, on soils that have been developed from sedimentary rocks such as sandstones and marls. Vineyards here are growth on terraces made only of dry-stones, that represent a typical landscape element of this region (Figure 7).

The terraces have been restored since 2003 in order to maintain their original role of soil erosion prevention, and to realize the production of a very fine wine. Few months after the restoration, one of the terraces displayed deformations and slumps (Figure 8). This particular wall was therefore considered as an interesting element for the analysis described in the following chapters.

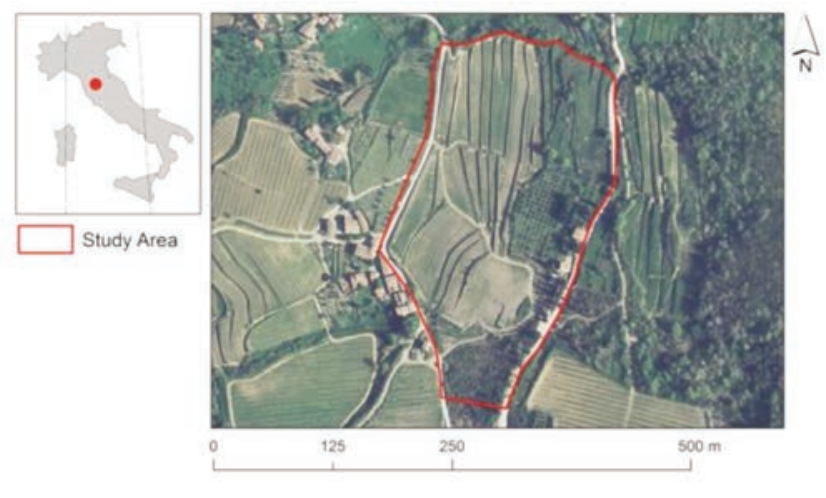

Figure 6. Geographical setting of study area of Lamole.

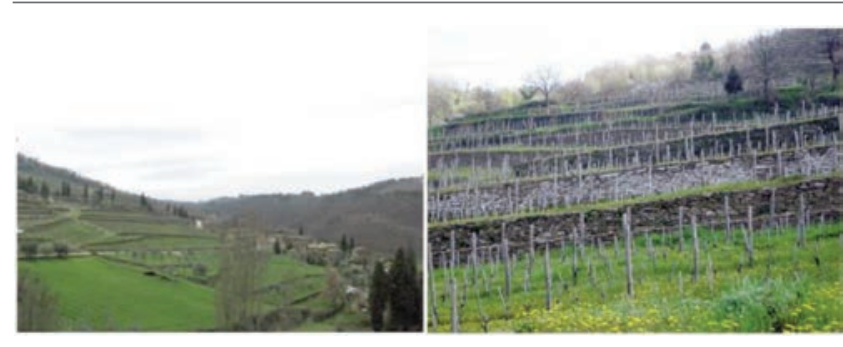

Figure 7. Panoramic picture of the Lamole area and its terraces.

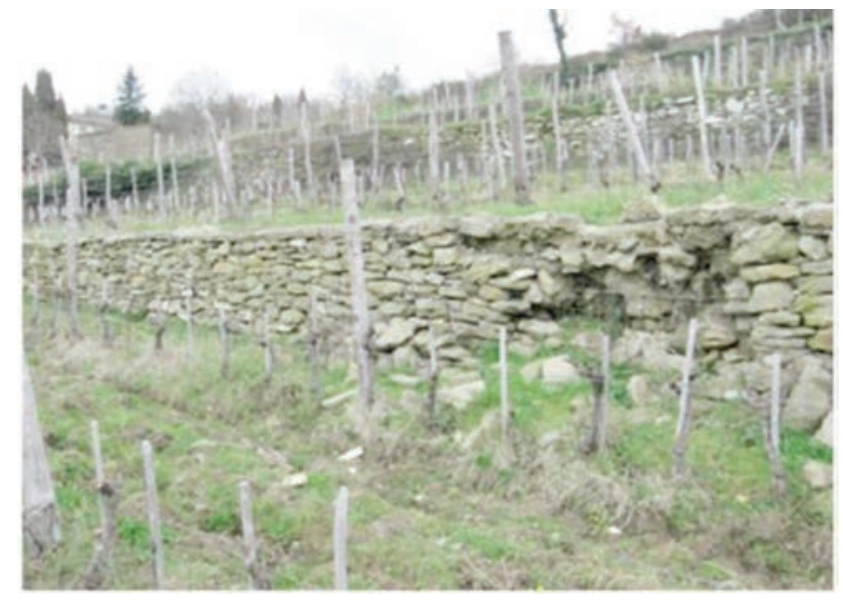

Figure 8. Surveyed terraced walls with slumps and erosion 


\section{Available data}

\section{Airborne LiDAR elevation data}

For the study area, a DTM with a $1 \mathrm{~m}$ resolution derived from Airborne LiDAR survey is available (Figure 9). This model is readily accessible to public authorities in Italy, and it is promoted by the Ministry for Environment, Land and Sea (Ministero dell'Ambiente $e$ della Tutela del Territorio e del Mare, MATTM), the Department of Civil Protection and the Mininstry of Defense, in agreement with the regional governments. The DTM has a horizontal accuracy of about $\pm 0.3 \mathrm{~m}$ and vertical accuracy of $\pm 0.15 \mathrm{~m}$ (RMSE estimated using DGPS ground truth control points).

\section{Results}

The lamole study case highlights the effectiveness of TLS surveys for two different analysis at least. The first is that the super resolute and

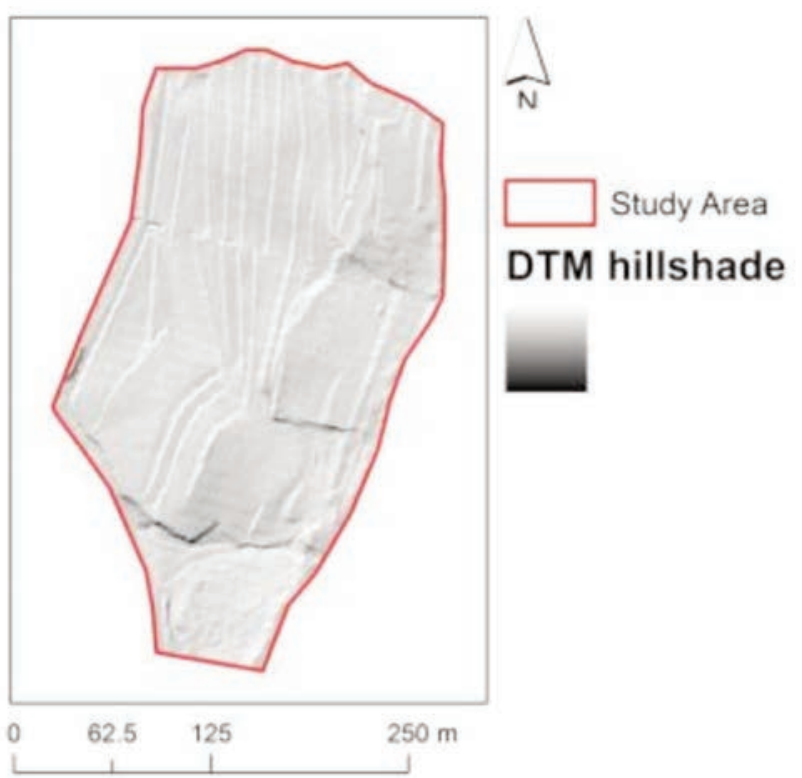

Figure 9. Airborne-LiDAR DTM (1m resolution) available for the study area.

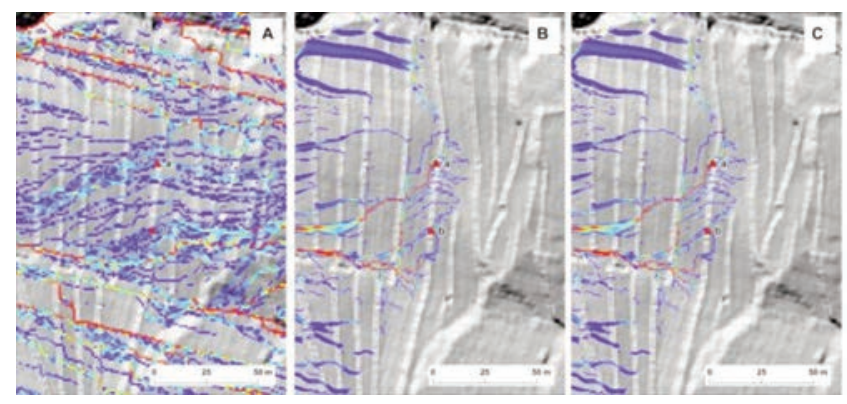

Figure 10. The RPII index evaluated using the ALS-Derived DTM with 1 m resolution (A) and the TLS DTMs with $0.5 \mathrm{~m} \mathrm{(B)}$ and $0.2 \mathrm{~m}(\mathrm{C})$ resolution. $a$ and $b$ represent the wall deformation surveyed on the field. systematic short range scan of a retaining wall allows the generation of a centimetric resolution 3D digital model of the wall with a very high accuracy. A model with this high resolution could be used in strengths and stability simulations. With centimeter wall-model, the behavior under soil pressure of the most of the stones can be correctly simulated and therefore, the final results might be more realistic than the results achievable with a totally artefacted wall-model.

The second result is the RPII index calculation. Figure 10 shows the RPII index evaluated using the ALS-Derived DTM with $1 \mathrm{~m}$ resolution (A) and the TLS DTMs with $0.5 \mathrm{~m}(\mathrm{~B})$ and $0.2 \mathrm{~m}$ (C) resolution.

Using a common ALS-derived DTM, the RPII does not detect any flow alteration, and so any soil erosion, due to terraces and any possible damage to the retaining walls (Figure $10 \mathrm{~A}$ ). With a TLS survey derived topographic base of $0.5 \mathrm{~m}$ resolution (Figure 10B) results are better but not yet completely satisfactory: just the most intense flow alterations are shown in the RPII map. In the RPII map of the terraced slope of Lamole a strong flow concentration is shown in corresponding of slump of the surveyed retaining wall. But the high values of the index are reported only below the collapsed stretch of the wall, and this could clearly appear as a not univocal result. In the $0.2 \mathrm{~m}$ resolution RPII map (Fig. 10C) there is no doubts that the flow deviation and concentration in corresponding of the slump are processes beginning above the slump, and they are due to the presence of the above terraces. In the $0.2 \mathrm{~m}$ resolution RPII map a considerable increase of contributing area due to terraced morphology is reported also in corresponding of a deformed segment of the surveyed retaining wall.

\section{Conclusions}

This paper highlights the effectiveness of a centimetre resolution topography obtained from TLS survey in the analysis of terrace failure processes in vineyards. In the landscape of "Chianti classico" wine, the TLS has been proved to be a useful instrument to perform quickly high resolution and high accuracy topographic surveys. Interpolating the acquired points, two high resolution DTMs $(0.5 \mathrm{~m}$ and $0.2 \mathrm{~m}$ resolution) have been obtained, and then a simple morphometric and hydrological analysis is performed. Using a $0.2 \mathrm{~m}$ resolution TLS derived DTM, overflow convergences are recognizable exactly where in the field erosion evidence were surveyed. This proves that TLS and the derived high resolution topography can be a useful tool to improve the land use management and planning for the maintenance of terraced areas. However, this method needs to be improved, to clean the alteration that might derive from complex terraced morphology by thick vegetation and DTM artefacts.

\section{References}

Albani M., Klinkenberg B., Andison D.W., Kimmins J.P. 2004. The choice of window size in approximating topographic surfaces from digital elevation models. International Journal of Geographical Information Science, 18(6): 577-593.

Corell D.C., Thomas E., Jordan E., Weller D.E. 1999. Precipitation effects on sediment and associated nutrient discharges form Rhode river watersheds. Journal of Environmental Quality 28, 1897-1907.

Crosta G.B. 1998. Regionalization of rainfall threshold: an aid to landslides hazard evaluation. Env. Geol. 35 (2-3): 131-145.

Crosta G.B. and Frattini P. 2002. Rainfall threshold for triggering soil slips and debris flow. Proc. 2nd Plinius Int. Conf. on Mediterranean Storms, Siena, Italy, [in press].

Crosta G.B., Dal Negro P., Frattini P. 2003. Soil slips and debris flows on 
terraced slopes. Natural Hazards and Earth System Sciences 3: 3142.

Douglas C.L., King K.A., Zuzel J.F. 1998. Nitrogen and phosphorous in surface runoff and sediment from a wheat-pea rotation in northeastern Oregon. Journal of Environmental Quality 27: 1170-1177.

Evans I.S. 1979. An integrated system of terrain analysis and slope mapping. Final report on grant DA-ER0-591-73-G0040, University of Durham, England.

Florinsky I.V. 1998. Accuracy of local topographic variables derived from digital elevation models. International Journal of Geographical Information Science 12(1): 47-61.

Lin C.W., Tseng C.M., Tseng Y-H., Fei L.Y., Hsieh Y.C., Tarolli P. 2013. Recognition of large scale deep-seated landslides in forest area of Taiwan using high resolution topography. Journal of Asian Earth Sciences 62: 389-400.

Martìnez-Casanovas J.A., Concepcion Ramos M., Ribes-Dasi M. 2005. On-site effects of concentration flow erosion in Vineyard fields: some economic implications. Catena 60: 129-146.

Moser M. and Hoensisnn F. 1983. Geotechnical aspect of soil slips in Alpine regions. Eng. Geol. 19: 185-211.

Ng Kee Kwong K.F., Bholah A., Volcy L., Pynee K., 2002. Nitrogen and phosphorous transport by surface runoff from a silty clay loam soil under sugarcane in the humid tropical environmental of Mauritius. Agriculture, Ecosystems and Environment 91: 147-157.

Passalacqua P., Tarolli P., Foufoula-Georgiou E. 2010. Testing spacescale methodologies for automatic geomorphic feature extraction from lidar in a complex mountainous landscape. Water resources research, 46, W11535. doi:10.1029/2009WR008812.

Pirotti F., Tarolli P. 2010. Suitability of LiDAR point density and derived landform curvature maps for channel network extraction. Hydrological Processes 24: 1187-1197. doi: 10.1002/hyp.758.

Poesen J. and Hooke J.M. 1997. Erosion, flooding and channel management in the Mediterranean environments of southern Europe. Progress in Physical Geography 21: 157-199.

Ramos M.C., Martinez-Casanovas J.A. 2004. Nutrient losses from a Vineyard soil in Northeastern Spain caused by an extraordinary rainfall event. Catena 55: 79-90.

Roose E. 1996. Land Husbandry: Components and Strategy. 70 FAO Bulletin. Food and Agriculture Organization of the United Nations, Rome.
Sibson R. 1981. A brief description of natural neighbor interpolation (Chapter 2). In: V. Barnett Interpreting Multivariate Data. John Wiley, Chichester, 21-36.

Sofia G., Tarolli P., Cazorzi F, Dalla Fontana G. 2011. An objective approach for feature extraction: distribution analysis and statistical descriptors for scale choice and channel network identification. Hydrol. Earth Syst. Sci.; 15, 1387-1402,doi:10.5194/hess-15: 13872011.

Sofia G., Pirotti F., Tarolli P. (2013a). Variations in multiscale curvature distribution and signatures of LiDAR DTM errors, Earth Surf. Process. Landforms, DOI: 10.1002/esp.3363

Sofia G., Dalla Fontana G.,. Tarolli, P. (2013b). High-resolution topography and anthropogenic feature extraction: testing geomorphometric parameters in floodplains. Hydrol. Process. doi: 10.1002/hyp.9727.

Steegen A., Govers G., Takken I., Nachtergaele J., Poesen J., Merckx R. 2001. Factors controlling sediment and phosphorous export from two Belgian agricultural catchments. Journal of Environmental Quality 30: 1249-1258.

Tarboton D.G. 1997: A new method for the determination of flow directions and upslope areas in grid digital elevation models. Water Resources Research 33: 309-319.

Tarolli P. and Dalla Fontana G. 2009. Hillslope to valley transition morphology: new opportunities from high resolution DTMs. Geomorphology 113: 47-56.

Tarolli P., Arrowsmith J R., Vivoni E.R. 2009. Understanding earth surface processes from remotely sensed digital terrain models. Geomorphology 113: 1-3.

Tarolli P., Sofia G., Dalla Fontana G. 2012. Geomorphic features extraction from high resolution topography: landslide crowns and bank erosion. Natural Hazards 61: 65-83.

Tarolli P., Calligaro S., Cazorzi F., Dalla Fontana G. 2013. Recognition of surface flow processes influenced by road and trails in mountain areas using high-resolution topography. European Journal of Remote Sensing 46: 176-197.

Verstraeten G. and Poesen J. 2002. Regional scale variability in sediment and nutrient delivery from small agricultural watersheds. Journal of Environmental Quality 31: 870-879.

Woodward D.E. 1999. Method to predict cropland ephemeral gully erosion. Catena 37: 393-399. 